\title{
Elaboração e Avaliação de Projeto de Aprendizagem Apoiado em Jogos Educacionais Digitais: Um Relato de Experiência com Alunos em Alfabetização
}

\author{
Cláudio A. Passos ${ }^{1}$, Isabel Fernandes ${ }^{2}$, Ronaldo R. Goldschmidt ${ }^{1}$ \\ ${ }^{1}$ Seção de Engenharia da Computação. Instituto Militar de Engenharia. \\ Pça Gal. Tibúrcio, 80 - Praia Vermelha - Rio de Janeiro - RJ, 22290-270 \\ ${ }^{2}$ Centro Universitário Uniamérica \\ Av. das Cataratas, 1118 - Vila Yolanda - Foz do Iguaçu - PR, 85853-000 \\ cpassos.cp2@gmail.com, isabel@uniamerica.br, \\ ronaldo.rgoldaime.eb.br.
}

\begin{abstract}
This article reports the experience in the design of a learning project (LP) based on digital educational game (DEG) to support the literacy of forty students of a public elementary school in Rio de Janeiro. The report includes the steps followed by the school's social body in the collective construction of the LP. It also describes the DEG configured with the learning content produced by the students and the results of a heuristic evaluation of the game performed by a set of evaluators who did not participate in the project development process.

Resumo. Este artigo relata uma experiência de planejamento e elaboração colaborativa de um projeto de aprendizagem (PA) baseado na aplicação de um jogo educacional digital (JED) para apoio à alfabetização de quarenta alunos de uma escola pública do ensino fundamental do Rio de Janeiro. Além do detalhamento das etapas percorridas pelo corpo social escolar na construção coletiva do PA, o relato compreende ainda a descrição do JED configurado com o conteúdo de aprendizagem produzido pelos alunos e o resultado de uma avaliação heurística do jogo, realizada por um conjunto de avaliadores que não participaram do processo de elaboração do projeto.
\end{abstract}

\section{Introdução}

Cada vez mais, recursos de área de Tecnologia da Informação e Comunicação (TIC) vêm sendo utilizados na Educação com o intuito de auxiliar o processo de ensinoaprendizagem [Goldschmidt et al., 2014]. Neste contexto, merecem destaque os jogos educacionais digitais (JED) que têm sido adotados como ferramentas de apoio ao aprendizado nos mais diversos níveis educacionais [Paz et al., 2018].

Ramos e Rocha (2016) apresentam os JED como um tripé: jogos, diversão e cognição. Segundo esta perspectiva, a utilização dos JED contribui para o desenvolvimento infantil no que se refere à diversidade de processos mentais que são mobilizados: memória, concentração, atenção dividida e seletiva, percepção, raciocínio, linguagem, abstração, planejamento e resolução de problemas.

A utilização dos JED no âmbito escolar tem se mostrado interessante uma vez que, ao proporcionar a inserção do lúdico no processo de aprendizagem, torna o conhecimento lecionado mais interessante, interativo, significativo e desafiador 
VIII Congresso Brasileiro de Informática na Educação (CBIE 2019)

Anais do XXX Simpósio Brasileiro de Informática na Educação (SBIE 2019)

[Mesquita et al., 2018]. Como consequência, atrai e aumenta a motivação e o engajamento dos aprendizes durante o processo, favorecendo, desta forma, o aprendizado dos conteúdos escolares [Guarda e Goulart, 2018].

Como em qualquer atividade de ensino, para Guedes (2018), o emprego de um JED deve ser planejado antecipadamente, podendo por exemplo, fazer parte de um projeto de aprendizagem. Um projeto de aprendizagem (PA) se caracteriza pela definição de um tema do mundo real de interesse do público alvo, associado a uma problemática a ser tratada ao longo do tempo por meio de ações de reflexão, pesquisa e desenvolvimento por parte dos aprendizes e professores, e cujos resultados são avaliados periodicamente gerando feedbacks sucessivos [Goldschmidt et al., 2014], [Carvalho et al., 2012].

O planejamento de um PA baseado em JED deve compreender, dentre outros aspectos, a escolha do JED a ser utilizado, sua configuração e uma avaliação prévia quanto à sua adequação ao propósito pretendido com o projeto [Guedes, 2018]. Assim sendo, o presente artigo tem como objetivo relatar detalhadamente uma experiência no planejamento e na elaboração colaborativa de um PA baseado na aplicação de um JED para apoio ao processo de alfabetização em duas turmas do primeiro ano do ensino fundamental de uma escola pública federal do Rio de Janeiro. Este relato compreende as etapas de formulação do projeto, abrangendo desde a definição da questão norteadora (i.e., o tema a ser estudado) até a avaliação do jogo selecionado, passando pelas etapas de seleção e configuração do JED. O relato contém ainda a descrição do JED configurado com o conteúdo de aprendizagem produzido pelos alunos e o resultado de uma avaliação heurística do jogo realizada por um conjunto de avaliadores que não participaram do processo de elaboração do projeto.

Para tanto, este texto encontra-se organizado em cinco seções. A Seção 2 apresenta fundamentos sobre projetos de aprendizagem. Detalhes sobre o relato de experiência no planejamento e na construção do PA e, sobre o JED configurado com o conteúdo de aprendizagem elaborado estão indicados nas Seções 3 e 4, respectivamente. A Seção 5 detalha os resultados do processo de avaliação do JED. E, por fim, a Seção 6 conclui o trabalho e apresenta alternativas de trabalhos futuros.

\section{Projetos de Aprendizagem}

Goldschmidt et al., (2014) define um PA como um projeto planejado e executado pelo corpo social escolar, envolvendo professores e estudantes, e que contém a descrição dos conteúdos e componentes curriculares, os objetivos de aprendizagem, a descrição das atividades que permitirão o desenvolvimento de tais objetivos, os recursos utilizados e os produtos que serão gerados. Autores como Bender (2014), Rafalski et al (2014), e Guedes (2018) destacam várias características positivas quanto à aplicação de PA nos processos educacionais, entre as quais, o trabalho colaborativo, a aprendizagem efetiva, os conhecimentos significativos, o desenvolvimento da criatividade, da lógica e da solução de problemas. Além disso, o uso de PA desperta o protagonismo e a proatividade estudantil, como também permite o uso de diversos recursos e tecnologias que, como os JED, levam a uma aprendizagem motivadora.

Embora a literatura atual não apresente um consenso completo quanto às etapas que compõem a construção de um PA, vários autores compartilham orientações e etapas em comum. A Tabela 1 resume como alguns deles interpretam as etapas de elaboração de um PA. Por meio dela, pode-se perceber os alinhamentos entre as óticas desses autores. 
VIII Congresso Brasileiro de Informática na Educação (CBIE 2019)

Anais do XXX Simpósio Brasileiro de Informática na Educação (SBIE 2019)

Tabela 1 - Resumo das etapas de construção de um PA, segundo alguns autores.

\begin{tabular}{|c|c|c|c|c|}
\hline Bender (2014) & $\begin{array}{c}\text { Carvalho et } a l . \\
\qquad(2005)\end{array}$ & $\underset{(2014)}{\text { Rafalski } \text { et } a l}$ & Guedes (2018) & $\underset{(\text { 2014) }}{\text { Goldschmidt }}$ et al \\
\hline $\begin{array}{l}\text { Definir tema } \\
\text { âncora para o PA }\end{array}$ & Escolher tema & $\begin{array}{l}\text { Escolher questão } \\
\text { de pesquisa }\end{array}$ & $\begin{array}{l}\text { Definir tema } \\
\text { âncora }\end{array}$ & $\begin{array}{l}\text { Escolher } \\
\text { conteúdos }\end{array}$ \\
\hline $\begin{array}{l}\text { Escolher questão } \\
\text { norteadora do PA }\end{array}$ & $\begin{array}{l}\text { Definir questões } \\
\text { de investigação }\end{array}$ & --- & $\begin{array}{l}\text { Escolher questão } \\
\text { motriz - problema } \\
\text { central }\end{array}$ & $\begin{array}{l}\text { Definir problema } \\
\text { a ser resolvido }\end{array}$ \\
\hline $\begin{array}{l}\text { Voz e escolha do } \\
\text { aluno }\end{array}$ & $\begin{array}{l}\text { Alunos negociam, } \\
\text { e algumas certezas } \\
\text { tornam-se dúvidas }\end{array}$ & $\begin{array}{l}\text { Alunos pesquisam } \\
\text { e professor } \\
\text { questiona e emite } \\
\text { feedback }\end{array}$ & $\begin{array}{l}\text { Sujeitos } \\
\text { participam de } \\
\text { forma ativa do } \\
\text { processo de } \\
\text { desenvolvimento } \\
\text { do PA }\end{array}$ & $\begin{array}{l}\text { Corpo social } \\
\text { docente define os } \\
\text { passos da } \\
\text { condução do } \\
\text { projeto }\end{array}$ \\
\hline $\begin{array}{l}\text { Pesquisa mediada } \\
\text { pelo professor e } \\
\text { aprofundamento } \\
\text { nas questões com } \\
\text { foco na inovação }\end{array}$ & Início da pesquisa & $\begin{array}{l}\text { Alunos buscam } \\
\text { responder às } \\
\text { questões de } \\
\text { investigação }\end{array}$ & $\begin{array}{l}\text { Educadores } \\
\text { estimulam os } \\
\text { discentes na } \\
\text { medida em que } \\
\text { eles avançam em } \\
\text { seu planejamento, } \\
\text { pesquisa e } \\
\text { desenvolvimento } \\
\text { de artefatos }\end{array}$ & --- \\
\hline $\begin{array}{l}\text { Oportunidades } \\
\text { para reflexão } \\
\text { sobre as decisões } \\
\text { de projeto e as } \\
\text { respostas à } \\
\text { questão } \\
\text { norteadora }\end{array}$ & --- & --- & $\begin{array}{l}\text { Processos de } \\
\text { reflexão. Os PA } \\
\text { desenvolvem } \\
\text { reflexão para } \\
\text { ponderação das } \\
\text { melhores soluções }\end{array}$ & --- \\
\hline $\begin{array}{l}\text { Feedback e } \\
\text { revisão professor- } \\
\text { aluno e aluno- } \\
\text { aluno }\end{array}$ & $\begin{array}{l}\text { Professor } \\
\text { questiona e } \\
\text { acompanha o } \\
\text { desenvolvimento } \\
\text { do projeto }\end{array}$ & $\begin{array}{l}\text { Acompanhamento } \\
\text { do } \\
\text { desenvolvimento } \\
\text { do projeto }\end{array}$ & $\begin{array}{l}\text { Feedback - } \\
\text { baseia-se no } \\
\text { processo de } \\
\text { avaliação } \\
\text { (educador, } \\
\text { avaliações pelos } \\
\text { alunos) }\end{array}$ & $\begin{array}{l}\text { Os professores } \\
\text { revisam o projeto } \\
\text { e emitem } \\
\text { feedback }\end{array}$ \\
\hline $\begin{array}{l}\text { Apresentação } \\
\text { pública dos PA }\end{array}$ & $\begin{array}{l}\text { Publicação dos } \\
\text { projetos }\end{array}$ & $\begin{array}{l}\text { Publicação digital } \\
\text { dos projetos }\end{array}$ & --- & $\begin{array}{l}\text { Publicação do } \\
\text { projeto }\end{array}$ \\
\hline
\end{tabular}

\section{O Relato de Experiência}

O presente relato descreve a experiência de elaboração colaborativa de um PA envolvendo duas docentes e quarenta alunos em fase de alfabetização distribuídos em duas turmas. $\mathrm{O}$ estudo foi realizado no contexto de uma escola pública de referência no ensino fundamental do Rio de Janeiro e faz parte de um conjunto de trabalhos de pesquisa apoiado pela Memore-net.

A Memore-net ${ }^{1}$ é uma plataforma colaborativa de apoio à aprendizagem que permite, aos interessados em educação apoiada por computador, interagir, formar grupos

${ }^{1}$ Uma Rede Social para Compartilhamento de Experiências e Resultados na Utilização de Tecnologias da Informação e Comunicação na Educação 
de interesse, compartilhar experiências, aprender e aprimorar ações e políticas pedagógicas no uso das TIC em sala de aula. Entre suas funcionalidades principais estão o suporte à construção de projetos de aprendizagem e a oferta de jogos educacionais digitais cujo o conteúdo, objeto da aprendizagem, é configurável pelo professor.

A motivação para a elaboração do projeto de aprendizagem deste estudo decorreu das experiências de sala de aula, nas quais as professoras detectaram, em boa parte dos alunos, problemas na leitura convencional de pequenos textos. As dúvidas percebidas se davam em algumas sílabas complexas como, por exemplo, palavras com duas consoantes e uma vogal ou ainda uma consoante, uma vogal e outra consoante. Em muitos momentos, os estudantes necessitavam de ajuda para recuperarem o sentido do que leram. Deste modo, as docentes tiveram como objetivo construir um projeto de aprendizagem para trabalhar o ensino da leitura e escrita em crianças em fase de alfabetização.

Diante do cenário apresentado, o processo de construção do PA foi adaptado a partir das orientações e experiências descritas em Bender (2014), Rafalski et al(2014), Guedes (2018) e Goldschmidt et al (2014). As etapas deste processo estão representadas no diagrama de atividades (Bezerra, 2016) disposto na Figura 1. O detalhamento dessas etapas encontra-se a seguir.

A primeira etapa teve como objetivo a definição do tema âncora. Para tanto, as professoras apresentaram aos estudantes duas alternativas: objetos em geral (exemplo, mesa, cadeira, bola, etc) e animais. O tema mais votado e que gerou maior envolvimento dos alunos foi o de animais, tornando-se, assim, tema âncora para trabalhar a meta de aprendizagem.

A meta de aprendizagem foi definida pelas docentes responsáveis vinculadas às turmas. Tal definição ocorreu em função das dificuldades de leitura de palavras e frases curtas. Para alcançá-la, os seguintes objetivos de aprendizagem foram estabelecidos:

- Reconhecer letras e sílabas;

- Estabelecer relação entre unidades sonoras e suas representações gráficas;

- Ler palavras com estrutura silábica canônica e não canônica;

- Ler frases curtas;

- Reconhecer a finalidade do texto.

Em consonância com os objetivos definidos, as docentes escolheram um conjunto com quarenta e três animais a serem trabalhados nas atividades do PA. Os animais selecionados foram, por exemplo, cachorro, girafa, baleia, macaco, pato, gato, leão, entre outros.

O estudo da Memore-net e a escolha do jogo foram etapas executadas em conjunto. As professoras vinculadas às turmas, com o apoio e supervisão dos pesquisadores deste estudo, navegaram na rede social Memore-net e experimentaram os JED disponíveis, escolhendo, na sequência, o mais apropriado ao desenvolvimento dos objetivos de aprendizagem estabelecidos.

O jogo escolhido foi o "Formar Palavras" que é um jogo totalmente voltado à compreensão das palavras através de estímulos distintos (texto, imagem e som), porém complementares e importantes para alcançar alguns dos objetivos de aprendizagem estabelecidos previamente. A Seção 4 apresenta maiores detalhes sobre o JED escolhido. 
VIII Congresso Brasileiro de Informática na Educação (CBIE 2019)

Anais do XXX Simpósio Brasileiro de Informática na Educação (SBIE 2019)

A etapa de construção do conteúdo de aprendizagem do JED ocorreu de forma colaborativa. Para tanto, foram realizadas duas oficinas de oitenta minutos (uma para cada turma) cujo objetivo foi preencher fichas com informações sobre os animais, a serem posteriormente utilizadas na configuração do jogo.

Cada ficha continha o nome, uma curiosidade e o desenho do animal que cada aluno deveria pesquisar, de acordo com a lista de animais preestabelecida pelas docentes. Cada criança preencheu a sua ficha a partir de pesquisas feitas em livros disponíveis na sala de aula.

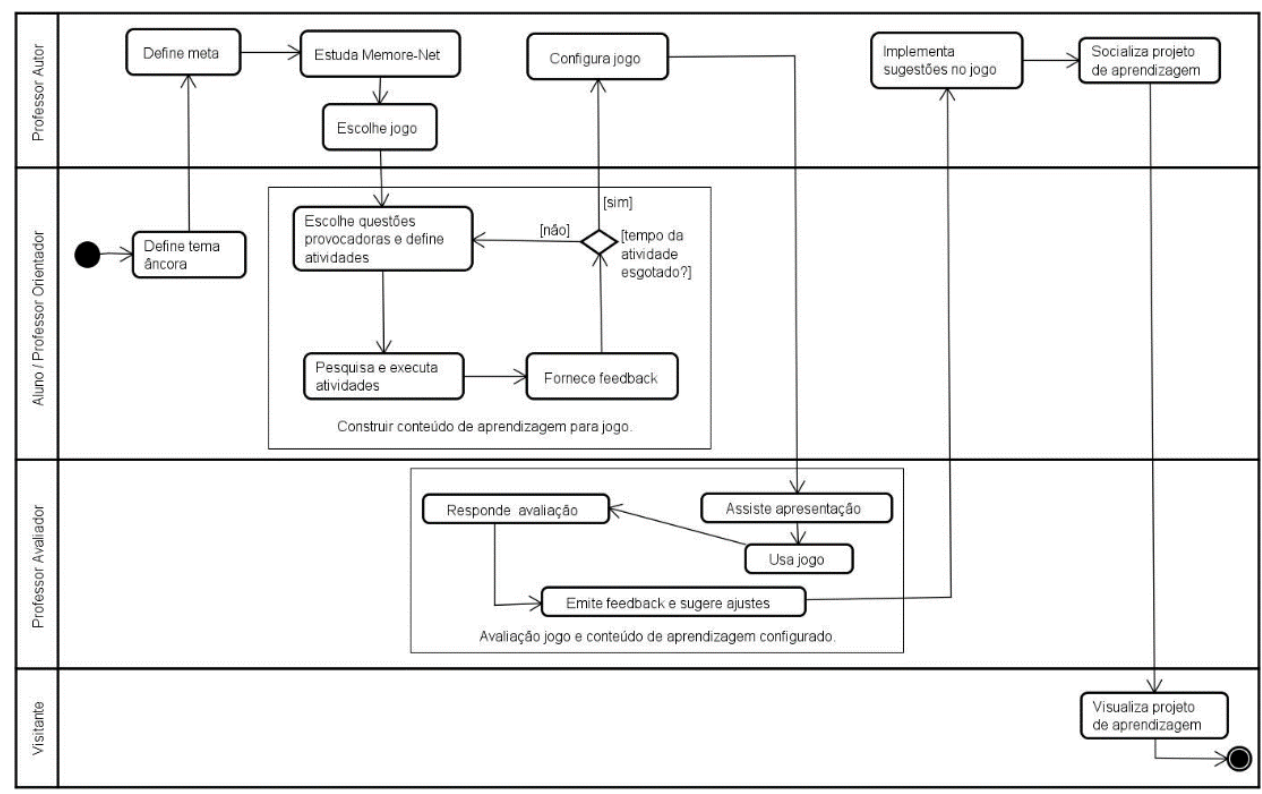

Figura 1: Etapas do processo de planejamento e construção do PA relatado neste artigo

A ênfase não foi colocada na pesquisa, e sim na escrita do nome do animal e da curiosidade sobre ele. Durante a etapa, as docentes estimularam os alunos na execução das atividades por meio de questões provocadoras como, por exemplo, "O que girafa tem de diferente dos outros animais?". Na medida em que os alunos executavam suas atividades, as professoras forneciam feedbacks específicos. As fotos da Figura 2 mostram os alunos desenhando e pesquisando sobre os animais durante a aula.
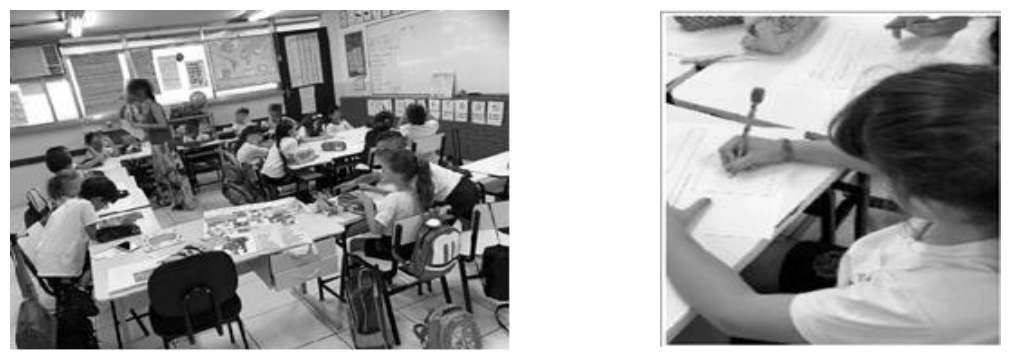

Figura 2 - Alunos desenhando e pesquisando sobre curiosidades dos animais.

Os alunos, ao saberem que os resultados de suas atividades em sala de aula seriam incluídos no jogo, mostraram-se bastantes envolvidos, motivados e colaborativos nas execuções das tarefas. A Figura 3 ilustra uma ficha preenchida. Note, no exemplo, o feedback dado ao estudante por uma das docentes: a indicação da falta da letra "A" na palavra "GRANDE". 
VIII Congresso Brasileiro de Informática na Educação (CBIE 2019)

Anais do XXX Simpósio Brasileiro de Informática na Educação (SBIE 2019)

Uma vez preenchidas todas as fichas, a etapa seguinte foi configurar o jogo com o conteúdo de aprendizagem elaborado na etapa anterior. Para tanto, as docentes acessaram o módulo da Memore-net que permite a configuração de jogos. A Figura 4(a) ilustra o cadastramento da ficha do exemplo da Figura 3. A Figura 4(b), por sua vez, mostra na Memore-net uma visão parcial da lista dos conteúdos elaborados pelos alunos já cadastrados na plataforma.

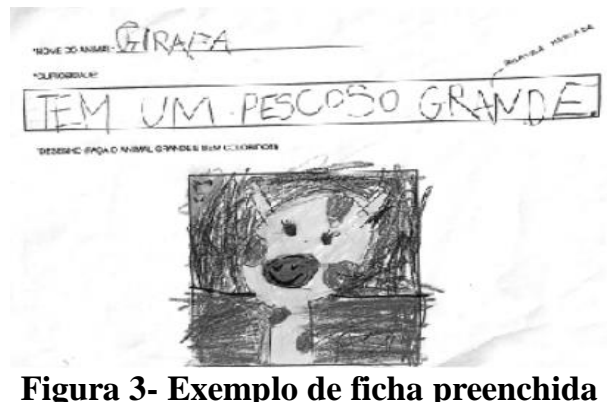

Uma vez cadastrada no banco de dados da Memore-net, a configuração do jogo pode ser utilizada pelos estudantes e demais usuários sempre que o mesmo for iniciado e a referida configuração for selecionada.

Antes da utilização como ferramental pedagógico pela comunidade acadêmica escolar, era de suma importância que o JED e o conteúdo configurado fossem avaliados formalmente. Assim sendo, a etapa seguinte teve por objetivo realizar tal avaliação.

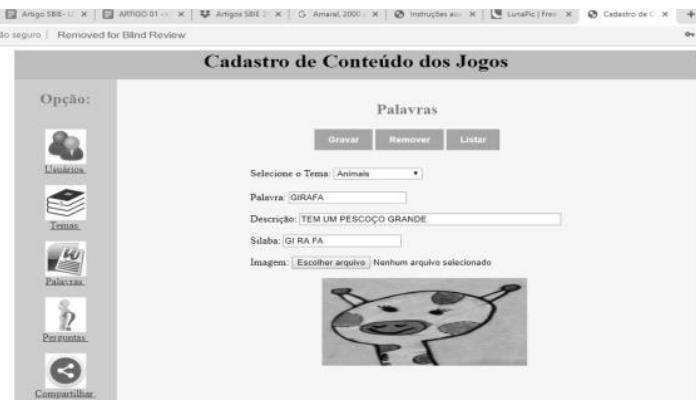

(a)

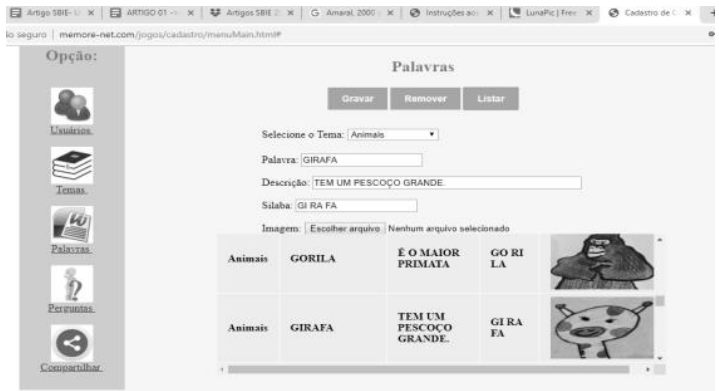

(b)

Figura 4 - Interfaces: (a) Cadastro de uma nova ficha; (b) Lista de fichas cadastradas

Para avaliar o jogo, foi formada uma banca com cinco professores do Ensino Fundamental I, sendo todos com experiência em regimentos de turmas com perfil semelhante às do presente estudo. A escolha da quantidade de avaliadores tomou como base os limites indicados por Nielsen (1995). Cabe ressaltar que, embora os avaliadores fizessem parte do corpo social da escola, nenhum deles participou das etapas de elaboração do PA ora descrito.

O primeiro passo de avaliação do JED foi a realização junto aos avaliadores de um workshop de apresentação da Memore-net e do jogo configurado. Após a apresentação, os avaliadores tiveram a oportunidade de jogar por vinte minutos e também de visualizar o conteúdo do jogo por meio do módulo de configuração disponível na Memore-net, ilustrado na Figura 4.

Após o workshop, os avaliadores foram apresentados a um questionário cujas perguntas foram baseadas em uma versão adaptada da heurística para avaliação de JED proposta em Annetta (2010). Denominada Heuristic Evaluation for Digital Educational 
VIII Congresso Brasileiro de Informática na Educação (CBIE 2019)

Anais do XXX Simpósio Brasileiro de Informática na Educação (SBIE 2019)

Games (HEDEG), tal heurística tem sido adotada na avaliação de diversos jogos educacionais (Valle et. al, 2013). De forma análoga ao proposto por Annetta (2010), as perguntas foram organizadas em categorias conforme ilustrado na Tabela 2.

Tabela 2: Categorias e Exemplos de Perguntas do Instrumento de Avaliação

\begin{tabular}{|l|l|l|}
\hline Categoria & \multicolumn{1}{|c|}{ Descrição } & \multicolumn{1}{|c|}{ Exemplo de pergunta } \\
\hline Interface & $\begin{array}{l}\text { Compreende perguntas relacionadas aos } \\
\text { elementos que permitem a comunicação } \\
\text { entre alunos e ambiente do jogo. }\end{array}$ & $\begin{array}{l}\text { Os elementos existentes no jogo são } \\
\text { consistentes e padronizados? }\end{array}$ \\
\hline $\begin{array}{l}\text { Elementos } \\
\text { Educacionais }\end{array}$ & $\begin{array}{l}\text { Consiste em perguntas relacionadas aos } \\
\text { elementos que permitem a construção de } \\
\text { conhecimentos por parte dos alunos. }\end{array}$ & $\begin{array}{l}\text { O jogo oferece ao usuário a possibilidade } \\
\text { de jogabilidade em todas as fases da } \\
\text { consciência fonológica, ao nível silábico? }\end{array}$ \\
\hline Conteúdo & $\begin{array}{l}\text { Contém perguntas relacionadas aos } \\
\text { elementos de conteúdo das disciplinas, } \\
\text { que os alunos irão praticar no decorrer do } \\
\text { jogo }\end{array}$ & $\begin{array}{l}\text { As fases da consciência fonológica são } \\
\text { abordadas de forma clara e explícita, } \\
\text { permitindo o entendimento da tarefa? }\end{array}$ \\
\hline Jogabilidade & $\begin{array}{l}\text { Inclui perguntas relacionadas à } \\
\text { experiência do jogador durante a sua } \\
\text { interação com o jogo. }\end{array}$ & $\begin{array}{l}\text { As teclas de controle do jogo seguem } \\
\text { padrões de convenção? }\end{array}$ \\
\hline Multimídia & $\begin{array}{l}\text { Abrange perguntas relacionadas aos } \\
\text { elementos de multimídia do jogo, como } \\
\text { por exemplo, sons, imagens, vídeos, entre } \\
\text { outros. }\end{array}$ & $\begin{array}{l}\text { Os elementos de multimídia do jogo } \\
\text { contribuem com a apresentação do } \\
\text { conteúdo de aprendizagem, tornando-o } \\
\text { mais atrativo? }\end{array}$ \\
\hline
\end{tabular}

A fim de determinar o grau de severidade de cada problema encontrado, cada avaliador atribuiu para cada pergunta uma nota em uma escala de 0 a 4 , conforme mostrado na Tabela 3.

Tabela 3: Escala de Níveis de Severidade de Problemas

\begin{tabular}{|l|l|l|}
\hline 0 & Nenhum problema foi encontrado & Não é considerado um problema \\
\hline 1 & Problema estético & Não precisa ser corrigido a menos que haja tempo disponível \\
\hline 2 & Problema de baixa prioridade & Menor problema de usabilidade \\
\hline 3 & Problema de maior prioridade & Alta prioridade, necessita de correção \\
\hline 4 & Problema catástrofe & Não poderá ser utilizado antes da correção \\
\hline
\end{tabular}

Após a aplicação do instrumento de avaliação, os avaliadores emitiram alguns feedbacks voltados à melhoria do jogo. Entre os principais, podem ser destacadas duas sugestões relacionadas à categoria "Interface": (1) a inclusão de um botão para o aluno "pausar" o jogo e depois poder prosseguir do ponto em que parou; (2) sempre que um aluno não conseguir identificar uma palavra dentro do tempo cronometrado do jogo, esta deve ser exibida na tela de encerramento da jogada. Cabe ressaltar que não foram apresentadas sugestões de melhoria do conteúdo de aprendizagem configurado no jogo.

Para viabilizar a socialização do projeto de aprendizagem, este foi cadastrado no banco de dados da Memore-net por meio da funcionalidade "Elaboração de Projeto de Aprendizagem", conforme ilustrado na Figura 5. Uma vez cadastrado, o projeto de aprendizagem pode ser visualizado por visitantes da Memore-net ${ }^{2}$.

2 Para consultar o projeto de aprendizagem relatado neste artigo, acesse o link www.memorenet.com/download/projeto-20190828083232.pdf. 
VIII Congresso Brasileiro de Informática na Educação (CBIE 2019)

Anais do XXX Simpósio Brasileiro de Informática na Educação (SBIE 2019)

\section{O JED "Formar Palavras" e o Conteúdo de Aprendizagem}

O JED "Formar Palavras" consiste em um jogo, onde o professor escolhe um conjunto de palavras relacionadas a um tema âncora abordado em sala de aula para serem descobertas pelos alunos. As palavras são classificadas internamente por grau de dificuldade $^{3}$ e apresentadas com as letras embaralhadas.

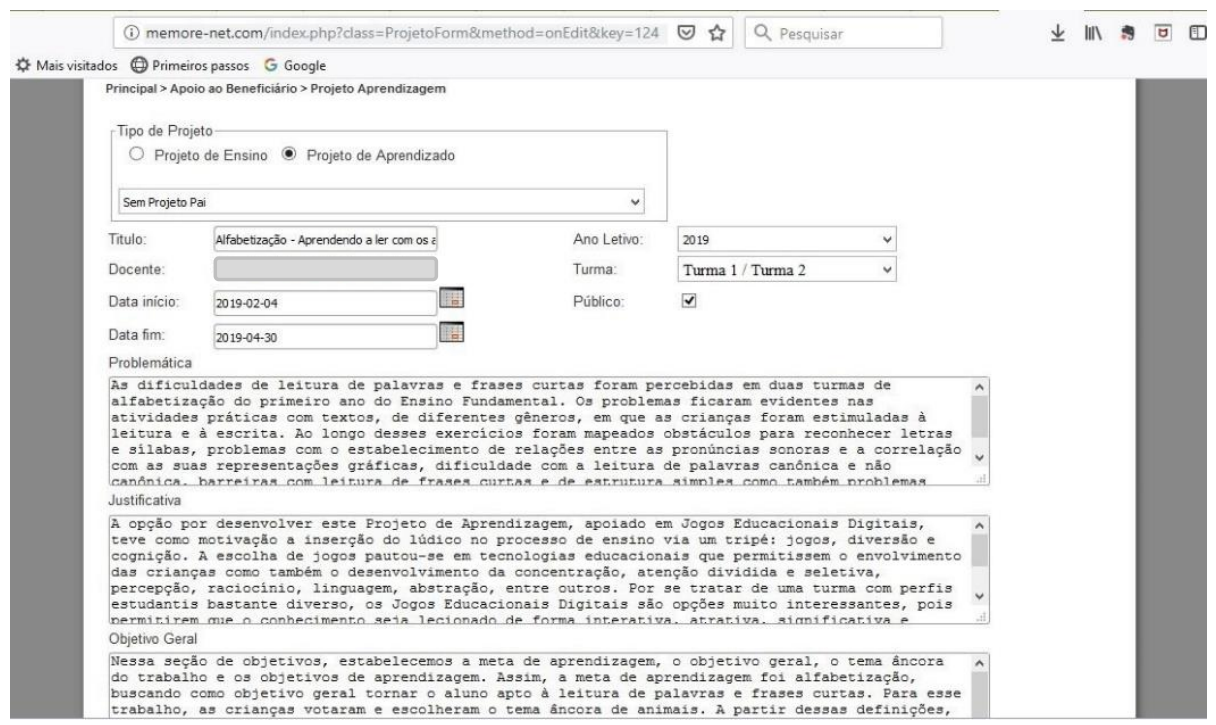

Figura 5 - Formulário para preenchimento do Projeto de Aprendizagem

O aluno, por sua vez, deve posicioná-las na ordem correta. O jogo disponibiliza cinco formas de jogar: somente palavras, na qual as palavras são apresentadas sem nenhuma forma de ajuda; palavras acompanhadas de imagem; palavras seguidas de uma dica; sílabas, onde cada palavra vem com suas sílabas embaralhadas; e, por último, a opção frase, onde as palavras que compõem a frase vêm embaralhadas. A Figura 6 ilustra a tela de opções do jogo em que o aluno escolhe o tema e a forma de jogar.

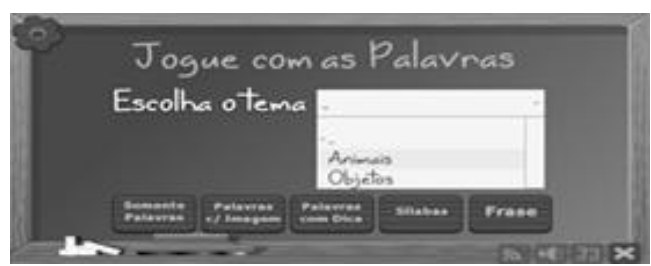

Figura 6 - Tela de opções do jogo

A Figura 7(a) mostra uma jogada quando a opção "Palavras com Imagens" é selecionada. As Figuras 7(b) e 7(c) apresentam as reações do jogo diante do resultado alcançado pelo aluno. Elas mostram, respectivamente, uma comemoração mediante um acerto e um lamento frente a um erro e consequentemente término do jogo. Outra forma de encerramento do jogo é quando o aluno conclui todas as fases dentro do tempo (vide Figura 7(d)). Importante observar que as imagens do exemplo ilustram parte do conteúdo do tema âncora "animais" configurado.

O jogo é composto de fases. Cada fase é montada dinamicamente, com palavras de mesmo número de letras. A quantidade de palavras por fase é, no máximo, cinco. A escolha das palavras de cada fase é aleatória e é realizada a partir do conjunto de palavras

\footnotetext{
${ }^{3} \mathrm{O}$ grau de dificuldade é medido pela quantidade de letras que compõe a palavra.
} 
VIII Congresso Brasileiro de Informática na Educação (CBIE 2019)

Anais do XXX Simpósio Brasileiro de Informática na Educação (SBIE 2019)

cadastradas pelo docente no banco de dados. Cabe ressaltar, neste ponto, que não há qualquer limite com relação ao número de palavras cadastradas por fase.

O jogo possui controle de tempo que estabelece um limite para o aluno completar a atividade. A estratégia de controle de tempo pode ser configurada de duas maneiras: limite de tempo para acertar uma única palavra ou limite de tempo para concluir uma fase. Em ambos os casos, o professor é quem delimita o tempo máximo da atividade.

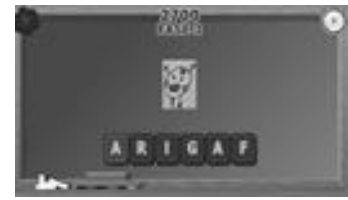

(a)

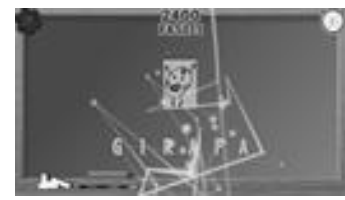

(b)

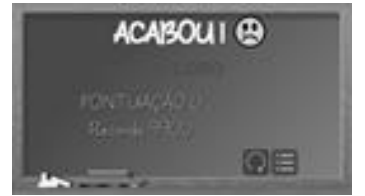

(c)

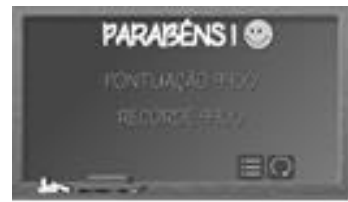

(d)

Figura 7 - Telas do jogo da opção "Palavras com Imagens": (a) jogada do aluno; (b) comemoração mediante acerto; (c) lamento mediante erro; (d) comemoração de conclusão

O jogo possui ainda uma estratégia de cálculo de pontuação. Quanto mais rápido o aluno conclui a atividade, maior a pontuação obtida por ele. Sempre que um aluno utiliza o jogo, seu desempenho é armazenado no banco de dados e pode ser consultado pelo professor quando necessário.

\section{Resultados do processo de avaliação do jogo}

A Tabela 4 sumariza os dados do questionário aplicado durante a etapa de avaliação do jogo. Na primeira coluna são apresentadas as categorias das perguntas formuladas. A segunda apresenta as médias do grau de severidade dos problemas encontrados nessas categorias. Essas médias foram obtidas da seguinte forma: i) calculouse a média aritmética dos graus de severidade atribuídos pelos avaliadores, por pergunta; e ii) posteriormente, calculou-se a média aritmética dos graus de severidade das perguntas que pertencem a uma mesma categoria.

Tabela 4 - Médias dos graus de severidade das categorias de perguntas respondidas

\begin{tabular}{|c|c|}
\hline Categoria & Avaliação \\
\hline Interface & 0,37 \\
\hline Elementos Educacionais & 0,25 \\
\hline Conteúdo & 0,16 \\
\hline Jogabilidade & 0,05 \\
\hline Multimídia & 0,03 \\
\hline
\end{tabular}

Ao analisar os resultados, percebe-se que todas as categorias tiveram avaliação próxima de zero, indicando, portanto, um elevado grau de adequação do jogo e de sua configuração ao propósito pretendido. É importante ressaltar que as duas únicas sugestões de melhoria dadas pelos avaliadores foram justamente com relação às interfaces (categoria com avaliação mais fraca). Ambas já foram implementadas e disponibilizadas.

\section{Considerações Finais}

O presente artigo apresentou um relato da experiência de planejamento e elaboração de um PA baseado na aplicação de um JED para apoio à alfabetização de duas turmas do primeiro ano do ensino fundamental de uma escola pública do Rio de janeiro. Cada uma das etapas de construção do projeto foi descrita em detalhes. Além disso, foram apresentados o jogo adotado, o conteúdo de aprendizagem elaborado pelos alunos e os 
VIII Congresso Brasileiro de Informática na Educação (CBIE 2019)

Anais do XXX Simpósio Brasileiro de Informática na Educação (SBIE 2019)

resultados da avaliação de ambos por uma banca de avaliadores que não participaram da construção do projeto. Os resultados indicam que o JED configurado está em condições de ser utilizado em sala de aula, dando continuidade ao desenvolvimento do PA.

Como iniciativas de trabalhos futuros estão: a avaliação do quanto a aplicação do jogo com a atual configuração pode influenciar na melhoria do aprendizado dos alunos, além do desenvolvimento de outros PA baseados em outros JED, em outros temas âncora e em outras turmas; a implementação na Memore-net de mecanismos de consolidação e relatórios de acompanhamento dos registros de utilização dos jogos, de maneira que a prática e o desempenho dos estudantes possam ser monitorados de forma contínua, por último, aprimorar a formalização do processo de avaliação dos JED pelos docentes.

\section{Referências}

Annetta, L. (2010) "The "I's" have it: A framework for serious educational game design" Review of General Psychology, vol. 14, no.2, p. 105-112.

Bender, W. N. (2014) “Aprendizagem Baseada em Projetos: Educação Diferenciada para o Século XXI”. Penso, Porto Alegre.

Bezerra, E. (2016) Princípios de Análise e Projeto de Sistema com UML. Elsevier Brasil.

Carvalho, M. J. S.; De Nevado, R. A.; De Menezes, C. S.(2005) "Arquiteturas pedagógicas para educação à distância: concepções e suporte telemático.” In: Brazilian Symposium on Computers in Education (SBIE). p. 351-360.

Cotonhoto, L. A.; Rossetti, C. B.(2016) "Prática de jogos eletrônicos por crianças pequenas: o que dizem as pesquisas recentes?”. Rev. psicopedag., São Paulo , v. 33, n. 102, p. 346-357.

Goldschmidt, R. R.; Souza, I. F.; Ribeiro, M. N. (2014) "Memore: um ambiente computacional para coleta e mineração de dados sobre o uso de computadores na educação." Rio de Janeiro: [s.n.].

Guarda, G. F.; Goulart, I. F.; (2018). "Jogos Lúdicos sob a ótica do Pensamento Computacional: Experiência do Projeto Logicamente". In: Brazilian Symposium on Computers in Education (SBIE).

Guedes, A. (2018) "Projeto de Aprendizagem Gamificado: Um Relato de Experiência." In: Brazilian Symposium on Computers in Education (SBIE). p. 635.

Mesquita, O. H.; Aranha, E. H. S.; Silva, T.R.; (2018). "Uma Abordagem para o Desenvolvimento de Jogos Digitais Educativos no Ensino Básico". In: Brazilian Symposium on Computers in Education (SBIE).

Nielsen, J. How to Conduct a Heuristic Evaluation. (1994). Disponível em: https://www.nngroup.com/articles/how-to-conduct-a-heuristic-evaluation/ Acesso em: 30 abr. 2019.

Paz, D. P; Franco, M.H.I.; Bertagnolli, S.C.; Costa, H.J.M.; (2018). ”Desenvolvimento e avaliação de um jogo digital educacional sobre aspectos socioculturais de países hispano falantes". In: Brazilian Symposium on Computers in Education (SBIE).

Rafalski, J. P.; Júnior, R. R. M. V.; Da Silva, C. A. S.(2014) "Mundos Virtuais como Suporte à Aprendizagem-Uma Avaliação na Implementação de Projetos de Aprendizagem." RENOTE, v. 12, n. 1.

Ramos, D. K.; Rocha, N. L. da. (2016) Avaliação do uso de jogos eletrônicos para o aprimoramento das funções executivas no contexto escolar. Rev. psicopedag., São Paulo, v. 33, n. 101, p. 133-143.

Valle, P. et.al.(2013) "HEDEG - Heurísticas para avaliação de jogos educacionais digitais.” Nuevas Ideas em Informática Educativa, TISE 2013, Porto Alegre. 